\title{
Simplification of an MCNP model designed for dose rate estimation
}

\author{
Alexander Laptev ${ }^{1}$ and Robert Perry ${ }^{1,2, *}$ \\ ${ }^{1}$ Los Alamos National Laboratory, P.O. Box 1663, Los Alamos, NM 87545 \\ ${ }^{2}$ Present: GAEA Scientific, 394 Catherine Ave., Los Alamos, NM 87544
}

\begin{abstract}
A study was made to investigate the methods of building a simplified MCNP model for radiological dose estimation. The research was done using an example of a complicated glovebox with extra shielding. The paper presents several different calculations for neutron and photon dose evaluations where glovebox elements were consecutively excluded from the MCNP model. The analysis indicated that to obtain a fast and reasonable estimation of dose, the model should be realistic in details that are close to the tally. Other details may be omitted.
\end{abstract}

\section{Introduction}

Gloveboxes are often the subject of radiological engineering design reviews. The Monte Carlo N-Particle transport code, MCNP, [1] is the primary tool used to estimate a worker's external dose from radiological activities performed in a glovebox. Coding a complete glovebox model is very time consuming. This research provides a technical analysis of the changes in the results following several simplifications of a complete glovebox MCNP model. It provides insight on how to efficiently build a simple glovebox model that adequately describes the problem resulting in considerable savings of time.

\section{Original MCNP Model}

The glovebox model under discussion is a complex glovebox with several layers of protective shielding (lead and polymethyl methacrylate, PMMA) and water doors underneath it. Both the front and back of the glovebox had three upper and lower workstations with a total of six workstations. Each work station had a single window and two glove ports. Three larger windows were located between the three upper and lower workstations. All the windows were made from leaded glass. The gloves used in the model were leaded. An airlock port was located on both ends of the glovebox.

The model contained four 200 gram plutonium-238 dioxide sources. It was assumed that two sources would be bare plutonium-238 dioxide and these sources were centered in each half of the glovebox. The remaining two sources were encased in steel containers and placed in opposing front corners of the glovebox.

To characterize the radiation field, three torso-sized tallies were used. The three tallies are hereby referred to as Tally \#1, Tally \#2, and Tally \#3. Tally \#1 was placed against the center of the bottom row of the middle workstation at a distance of $1 \mathrm{~mm}$ from the additional shielding. Tally \#2 was placed in an identical location as Tally \#1 with the only difference being Tally \#2 was placed $30 \mathrm{~cm}$ away instead of $1 \mathrm{~mm}$. Tally \#3 was placed against the center of the bottom row of the right workstation at a distance of $1 \mathrm{~mm}$ from the additional shielding. Tally \#1 matches the most probable worker's position. The position of Tally \#3 was selected to characterize the dose rate at the right workstation (it is the also the same for the left workstation). The dose rate at the right and left workstations is expected to be higher because of the spare source is placed in each front corner of the glovebox.

The original model of the glovebox is presented in Fig. 1. The yellow box represents the concrete floor of the room. The steel walls and waters doors of the glovebox are shown in blue with red glove ports (leaded gloves) and green windows. The outer layers of additional shielding (lead, stainless steel, and PMMA) are shown in pink. One of the two bare plutonium-238 oxide sources, which is visible inside of the glovebox, is shown as a small, yellow, horizontal cylinder while one of the two contained sources is shown as a small, grey, vertical cylinder. The numbered, translucent squares are the tallies, and the wire frame represents the universe recognized by MCNP.

As mentioned, the original glovebox model was very complicated. The MCNP input geometry (cell, surface, and transformation cards) consisted of 1071 rows, and the number of lines is roughly proportional to the time spent by a developer programming. As much as $5 \cdot 10^{8}$ neutrons were simulated for the neutron dose rate calculation and $8.4 \cdot 10^{9}$ photons were simulated for the photon dose rate calculation. The CPU time required to process that many neutrons and photons, respectively, is 36,506 and 44,234 min. The estimated photon and neutron effective doses for Tallies \#1 through \#3 are

\footnotetext{
* Corresponding author: RTP@gaea-scientific.com
} 
shown in Table 1. The results have a statistical uncertainty of $\leq 0.1 \%$ for neutrons and $\leq 0.5 \%$ for photons.

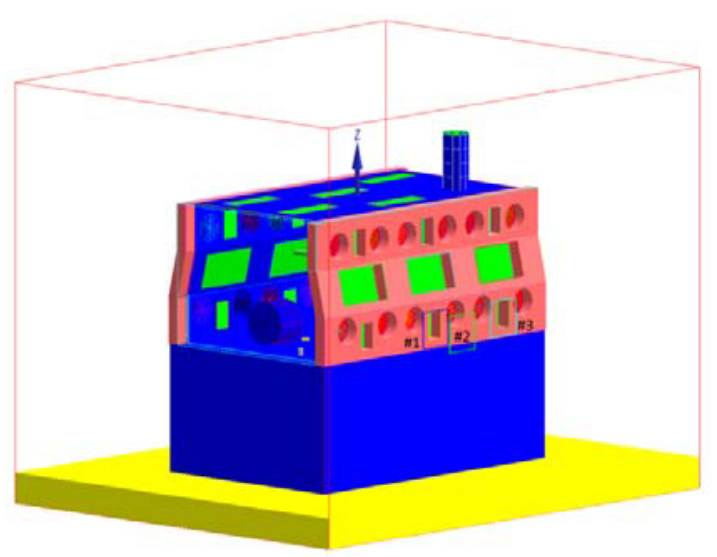

Fig. 1. Original MCNP model. The model includes the additional shielding, the tallies, the concrete floor, the four sources, all of the glovebox, and the water doors. The tallies are numbered. The left side of the glovebox and the additional shielding were removed in the figure to expose the two of the sources contained in the glovebox.

Table 1. Estimated Effective Dose Rates for Iteration 0.

\begin{tabular}{|c|c|c|}
\hline \multirow{2}{*}{$\begin{array}{c}\text { Tally } \\
\#\end{array}$} & \multicolumn{2}{|c|}{$\begin{array}{c}\text { Estimated Dose } \\
\text { Rates, } \mathbf{m r e m} / \mathbf{h r}\end{array}$} \\
\cline { 2 - 3 } & Photon & Neutron \\
\hline 1 & 0.302 & 4.76 \\
\hline 2 & 0.226 & 2.75 \\
\hline 3 & 0.577 & 9.97 \\
\hline
\end{tabular}

\section{Simplifying Iterations}

The simplification of the original model was made in a series of consecutive calculations. The list of calculations along with the number of lines in the MCNP input file are presented in Table 2. At each step in the simplification process the estimated photon and neutron doses are compared to both the original model and the previous calculation.

\subsection{Iteration 1: Reduced Outside World Boundaries}

For this iteration, the size of the modelled air universe that surrounded the glovebox was reduced (see Fig. 2). The advantage of limiting the universe was that the CPU time was decreased. For example, for the neutrons, CPU time was reduced by $24 \%$. The reduction in CPU time was attributed to particles that escaped the glovebox having fewer interactions outside of the glovebox.
Table 2. Simplifying iterations.

\begin{tabular}{|c|l|c|c|c|}
\hline \multirow{2}{*}{$\#$} & \multicolumn{1}{|c|}{ Description } & $\begin{array}{c}\text { M of } \\
\text { MCNP }\end{array}$ & \multicolumn{2}{|c|}{ CPU Time, min } \\
\cline { 4 - 5 } & & Photon & Neutron \\
\hline 1 & Original model & 1071 & 44,234 & 36,506 \\
\hline 2 & $\begin{array}{l}\text { Reduced Outside } \\
\text { World Boundaries }\end{array}$ & 1064 & 36,234 & 27,850 \\
\hline 3 & Single Wall and & 518 & 14,359 & 7,132 \\
\hline 4 & Single Wall & 513 & 15,874 & 6,525 \\
\hline 5 & $\begin{array}{l}\text { Simple Single Wall } \\
\text { Womoved Upper }\end{array}$ & 473 & 11,612 & 5,489 \\
\hline 6 & Remstations & 10,937 & 4,427 \\
\hline 7 & $\begin{array}{l}\text { Removed Gloves } \\
\text { Floor }\end{array}$ & 295 & 9,012 & 4,586 \\
\hline 8 & $\begin{array}{l}\text { Removed Water } \\
\text { Door }\end{array}$ & 278 & 9,384 & 2,972 \\
\hline $8^{*}$ & $\begin{array}{l}\text { Additional Iteration: } \\
\text { Removed Water } \\
\text { Doors with Floor } \\
\text { (Comparison with }\end{array}$ & 283 & 9,433 & 3,283 \\
\hline Iteration 6) & 290 & 8,285 & 3,221 \\
\hline
\end{tabular}

Also the MCNP input file was reduced slightly to 1064 lines by ignoring unnecessary details such as the filter case on the top of the glovebox.

The observed change in the dose rates was less than $0.3 \%$ in absolute value (Table 3 ). The decrease reflected less of a contribution from radiation being scattered off the air surrounding the glovebox towards the tallies. Fig. 3 presents the change in the neutron dose rates, the MCNP input file size, and CPU time observed during current iteration.

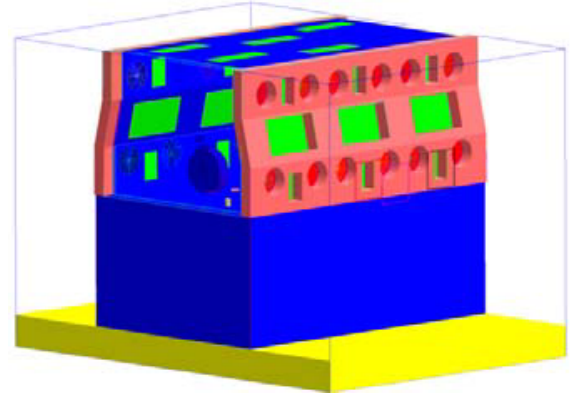

Fig. 2. MCNP glovebox model for Iteration 1: Reduced outside world boundaries.

\subsection{Iteration 2: Single Wall and Bottom}

This iteration simplified the glovebox model to only the front (with additional shielding) and bottom of the glovebox, the front of the water door, the concrete floor, and the sources (see Fig. 4). This iteration decreased the 
size of input file down to 518 lines and the CPU time to 7,132 and 14,359 minutes, for neutron and photon doses respectively.

Table 3. Estimated Effective Dose Rates for Iteration 1: Reduced outside world boundaries.

\begin{tabular}{|c|c|c|c|c|}
\hline \multirow{2}{*}{$\begin{array}{c}\text { Tally } \\
\#\end{array}$} & \multicolumn{2}{|c|}{$\begin{array}{c}\text { Estimated Dose } \\
\text { Rates, mrem/hr }\end{array}$} & \multicolumn{2}{c|}{$\begin{array}{c}\text { Percent Change vs } \\
\text { Iteration 0 }\end{array}$} \\
\cline { 2 - 5 } & Photon & Neutron & Photon & Neutron \\
\hline 1 & 0.302 & 4.75 & -0.0 & -0.1 \\
\hline 2 & 0.226 & 2.74 & -0.2 & -0.3 \\
\hline 3 & 0.576 & 9.96 & -0.1 & -0.1 \\
\hline
\end{tabular}

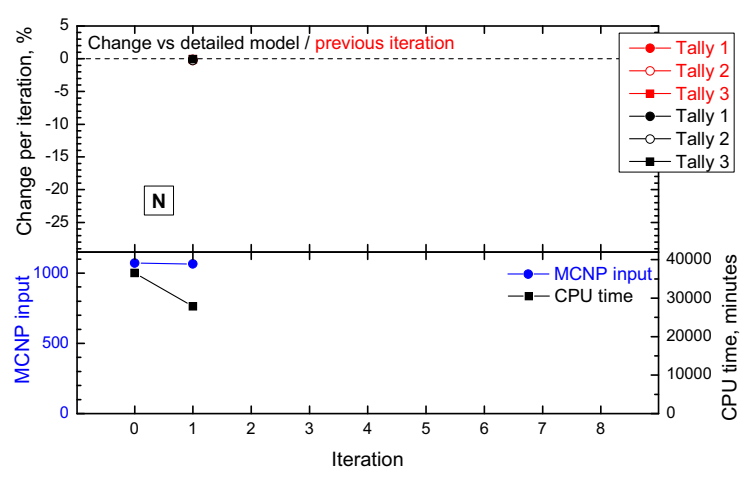

Fig. 3. The change in the neutron dose rates (upper plot) as well as the MCNP input file size and CPU time (lower plot) observed during Iteration \#1.

The estimated photon and neutron effective doses and their relative change from both Iteration 0 and Iteration 1 are shown in Table 4 . The change in the dose rates was noticeable, especially in the neutron dose rate, which changed approximately $10 \%$. The $10 \%$ decrease in the neutron dose rate reflected a missing contribution from neutrons scattering off the thick additional shielding external of the glovebox towards the tallies. Although it was not as prominent, a similar effect was seen for photons. Fig. 5 presents the change in the neutron dose rates, the MCNP input file size, and CPU time observed during current iteration.

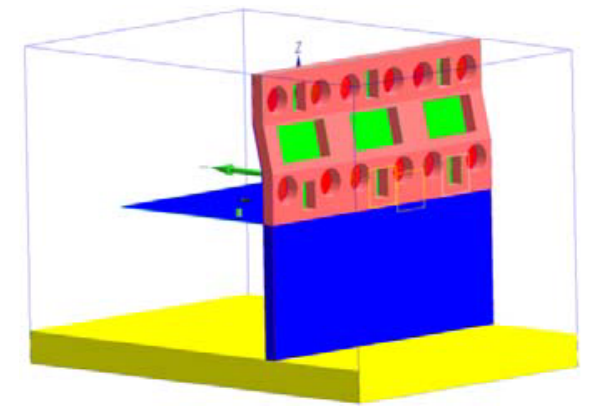

Fig. 4. MCNP glovebox model for Iteration 2: Single Wall and Bottom.
Table 4. Estimated Effective Dose Rates for Iteration 2: Single Wall and Bottom.

\begin{tabular}{|c|c|c|c|c|}
\hline \multirow{2}{*}{$\begin{array}{c}\text { Tally } \\
\#\end{array}$} & \multicolumn{2}{|c|}{$\begin{array}{c}\text { Estimated Dose } \\
\text { Rates, } \mathbf{~ m r e m} / \mathbf{h r}\end{array}$} & \multicolumn{2}{c|}{$\begin{array}{c}\text { Percent Change vs } \\
\text { Iteration 0 / 1 }\end{array}$} \\
\cline { 2 - 5 } & Photon & Neutron & Photon & Neutron \\
\hline 1 & 0.297 & 4.30 & $-1.6 /-1.5$ & $-9.7 /-9.6$ \\
\hline 2 & 0.220 & 2.38 & $-2.5 /-2.3$ & $-13.5 /-13.2$ \\
\hline 3 & 0.569 & 9.11 & $-1.3 /-1.3$ & $-8.6 /-8.5$ \\
\hline
\end{tabular}

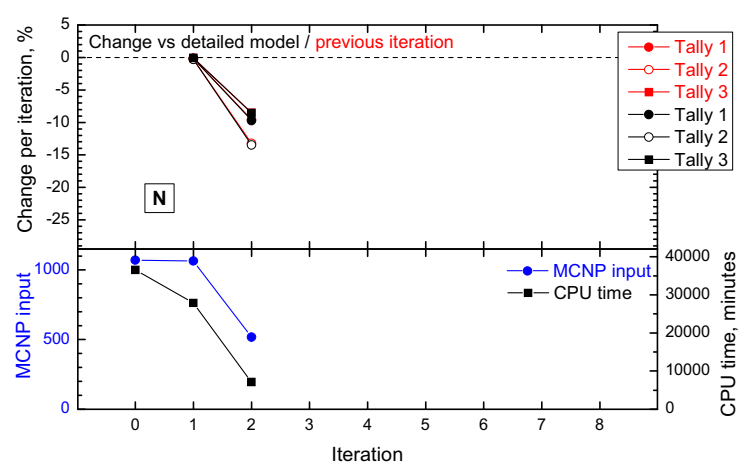

Fig. 5. The change in the neutron dose rates (upper plot) as well as the MCNP input file size and CPU time (lower plot) observed during Iteration $\# 2$.

\subsection{Iteration 3: Single Wall}

In this iteration, the glovebox bottom was removed from the model, leaving only the front wall (with additional shielding), the front of the water door, the sources, and the concrete floor (see Fig. 6). The size of input file was reduced to 513 lines. The CPU time was decreased by $9 \%$ for neutrons but increased by $11 \%$ for photons (compare with Iteration 2). The increase in the photons CPU time indicated that some photons, which were attenuated by the bottom of the glovebox in Iteration 2, were traced for a larger number of interactions and, therefore, more CPU time was used.

The estimated photon and neutron effective doses and their relative change from both Iteration 0 and Iteration 2 are shown in Table 5. Once again, the change in the neutron dose rate was nearly $10 \%$. The noticeable change in the neutron dose rate reflected a missing contribution from neutrons being scattered off the bottom of the glovebox. This effect was similar to the removal of the thick additional shielding in Iteration 2.

The photon dose rate profile was altered by this simplification. The dose rate decreased in the tallies located close to glovebox (Tallies \#1 and \#3) and increased by more than $6 \%$ in Tally \#2. The photon dose rate decrease observed in Tallies \#1 and \#3 was identical to the mechanism that decreased the neutron dose rate: there were no photons being scattering off the bottom of the glovebox. The photon dose rate increase observed in Tally \#2 can be explained by more photons being free to 
scatter off the air and concrete floor since they were not attenuated by the bottom of the glovebox. Fig. 7 presents the change in the neutron dose rates, the MCNP input file size, and CPU time observed during current iteration.

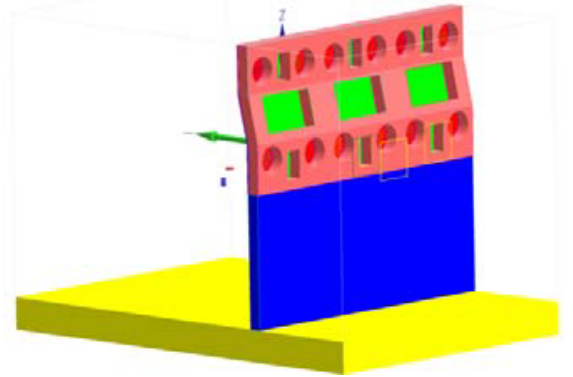

Fig. 6. MCNP glovebox model for Iteration 3: Single Wall.

Table 5. Estimated Effective Dose Rates for Iteration 3: Single Wall.

\begin{tabular}{|c|c|c|c|c|}
\hline \multirow{2}{*}{$\begin{array}{c}\text { Tally } \\
\#\end{array}$} & \multicolumn{2}{|c|}{$\begin{array}{c}\text { Estimated Dose } \\
\text { Rates, mrem/hr }\end{array}$} & \multicolumn{2}{c|}{$\begin{array}{c}\text { Percent Change vs } \\
\text { Iteration 0 / 2 }\end{array}$} \\
\cline { 2 - 5 } & Photon & Neutron & Photon & Neutron \\
\hline 1 & 0.287 & 3.85 & $-5.2 /-3.7$ & $-19.1 /-10.3$ \\
\hline 2 & 0.234 & 2.31 & $3.7 / 6.4$ & $-16.1 /-3.1$ \\
\hline 3 & 0.558 & 8.31 & $-3.3 /-2.0$ & $-16.7 /-8.8$ \\
\hline
\end{tabular}

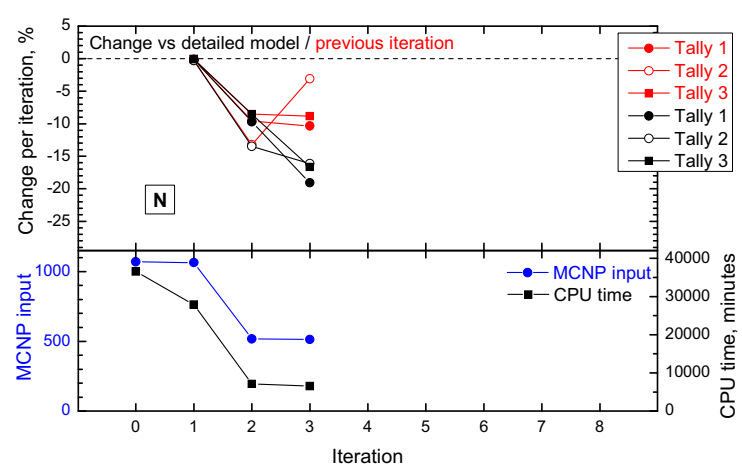

Fig. 7. The change in the neutron dose rates (upper plot) as well as the MCNP input file size and CPU time (lower plot) observed during Iteration \#3.

\subsection{Iteration 4: Simple Single Wall}

In this iteration, the front wall was simplified by replacing the complex, angled wall with a straight, simple wall (see Fig. 8). This iteration reduced the size of input file to 473 lines, and decreased the CPU time for neutrons by $16 \%$ and for photons by $27 \%$ (compare with Iteration 3).

The estimated photon and neutron effective doses and their relative change from both Iteration 0 and Iteration 3 are shown in Table 6 . The observed changes in dose rates were negligible compared to the previous iteration, allowing a conclusion to be drawn that geometrical particularities, such as a curvature, are not essential to the model. Fig. 9 presents the change in the neutron dose rates, the MCNP input file size, and CPU time observed during current iteration.

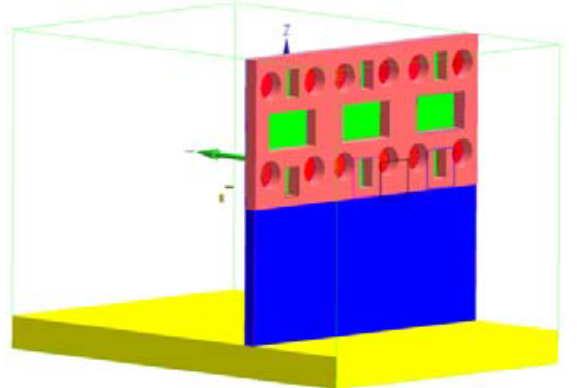

Fig. 8. MCNP glovebox model for Iteration 4: Simple Single Wall.

Table 6. Estimated Effective Dose Rates for Iteration 4: Simple Single Wall.

\begin{tabular}{|c|c|c|c|c|}
\hline \multirow{2}{*}{$\begin{array}{c}\text { Tally } \\
\#\end{array}$} & \multicolumn{2}{|c|}{$\begin{array}{c}\text { Estimated Dose } \\
\text { Rates, mrem/hr }\end{array}$} & \multicolumn{2}{c|}{$\begin{array}{c}\text { Percent Change vs } \\
\text { Iteration 0 / 3 }\end{array}$} \\
\cline { 2 - 5 } & Photon & Neutron & Photon & Neutron \\
\hline 1 & 0.286 & 3.86 & $-5.3 /-0.1$ & $-19.1 / 0.1$ \\
\hline 2 & 0.233 & 2.32 & $3.3 /-0.4$ & $-15.6 / 0.6$ \\
\hline 3 & 0.558 & 8.31 & $-3.3 / 0.0$ & $-16.7 / 0.0$ \\
\hline
\end{tabular}

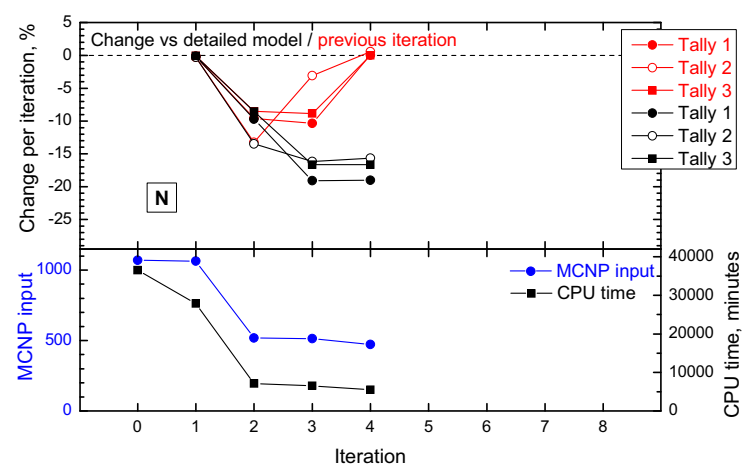

Fig. 9. The change in the neutron dose rates (upper plot) as well as the MCNP input file size and CPU time (lower plot) observed during Iteration \#4.

\subsection{Iteration 5: Removed Upper Workstations}

This iteration removed the upper three workstations from the model (see Fig. 10). This iteration simplified the input file down to 313 lines and subsequently decreased the CPU time for neutrons by 19\% (compare with Iteration 4). 
The estimated photon and neutron effective doses and their relative change from both Iteration 0 and Iteration 4 are shown in Table 7. Like the previous iteration, there was little change in either the photon or neutron dose rates. This proved that the location of the tallies was sufficiently far from the upper work stations to minimize the contribution from radiation that penetrated the top of the glovebox or that passed through the upper workstations. Fig. 11 presents the change in the neutron dose rates, the MCNP input file size, and CPU time observed during current iteration.

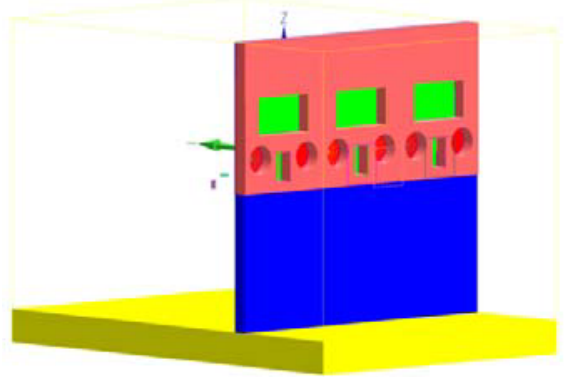

Fig. 10. MCNP glovebox model for Iteration 5: Removed Upper Workstations.

Table 7. Estimated Effective Dose Rates for Iteration 5: Removed Upper Workstations.

\begin{tabular}{|c|c|c|c|c|}
\hline \multirow{2}{*}{$\begin{array}{c}\text { Tally } \\
\#\end{array}$} & \multicolumn{2}{|c|}{$\begin{array}{c}\text { Estimated Dose } \\
\text { Rates, mrem/hr }\end{array}$} & \multicolumn{2}{c|}{$\begin{array}{c}\text { Percent Change vs } \\
\text { Iteration 0 / 4 }\end{array}$} \\
\cline { 2 - 5 } & Photon & Neutron & Photon & Neutron \\
\hline 1 & 0.286 & 3.85 & $-5.3 /-0.0$ & $-19.0 /-0.0$ \\
\hline 2 & 0.232 & 2.31 & $2.9 /-0.4$ & $-16.2 /-0.7$ \\
\hline 3 & 0.558 & 8.31 & $-3.3 /-0.0$ & $-16.7 /-0.0$ \\
\hline
\end{tabular}

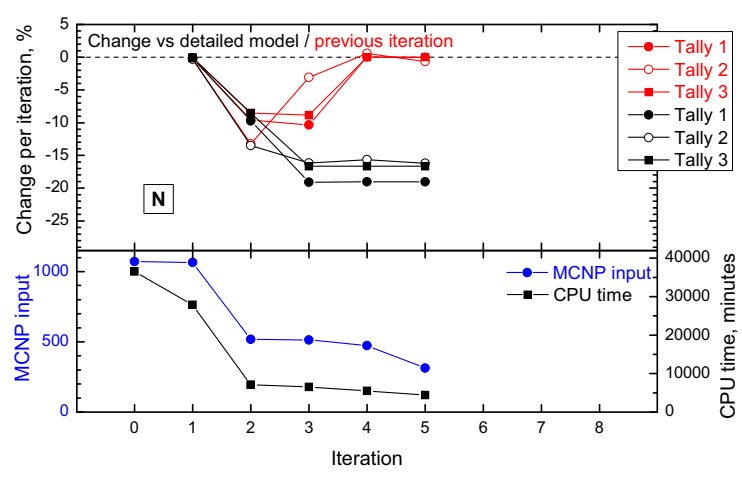

Fig. 11. The change in the neutron dose rates (upper plot) as well as the MCNP input file size and CPU time (lower plot) observed during Iteration $\# 5$.

\subsection{Iteration 6: Removed Gloves}

This iteration removed the leaded gloves from the lower glove ports (see Fig. 12). This simplification reduced the input file to 295 lines. The CPU time for neutrons was increased by $4 \%$ while for photons it reduced by $18 \%$ (compare with Iteration 5).

The estimated photon and neutron effective doses and their relative change from both Iteration 0 and Iteration 5 are shown in Table 8 . Observations showed that the change in the neutron dose rate was minimal but the photon dose rate increased significantly. The photon dose rate increase was the result of a significant contribution of low-energy photons (energy less than 25 $\mathrm{keV}$ ) emitted by the unshielded sources. Although the obtained result for photon dose is technically correct for the current MCNP model, it is not practical. In a real situation, those low-energy photons are easily attenuated by items like a source container, gloves, etc. Fig. 13 presents the change in the neutron dose rates, the MCNP input file size, and CPU time observed during current iteration.

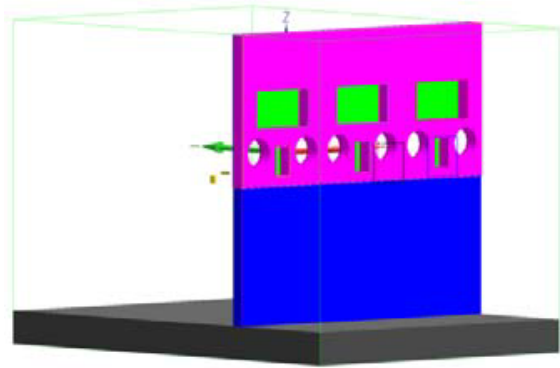

Fig. 12. MCNP glovebox model for Iteration 6: Removed Gloves.

Table 8. Estimated Effective Dose Rates for Iteration 6: Removed Gloves.

\begin{tabular}{|c|c|c|c|c|}
\hline \multirow{2}{*}{$\begin{array}{c}\text { Tally } \\
\#\end{array}$} & \multicolumn{2}{|c|}{$\begin{array}{c}\text { Estimated Dose } \\
\text { Rates, mrem/hr }\end{array}$} & \multicolumn{2}{c|}{$\begin{array}{c}\text { Percent Change vs } \\
\text { Iteration 0 / 5 }\end{array}$} \\
\cline { 2 - 5 } & Photon & Neutron & Photon & Neutron \\
\hline 1 & 0.495 & 3.89 & $64 / 73$ & $-18.4 / 0.8$ \\
\hline 2 & 0.926 & 2.32 & $310 / 299$ & $-15.8 / 0.5$ \\
\hline 3 & 0.759 & 8.31 & $32 / 36$ & $-16.6 / 0.1$ \\
\hline
\end{tabular}

\subsection{Iteration 7: Removed Floor}

The concrete floor was removed in this iteration (see Fig. 14). After the concrete floor was removed the size of the input file was reduced to 290 lines. Without the floor, there was less neutron and photon scattering. Thus, there were less interaction events and particles escaped the universe faster. Therefore, the CPU time reduced (compare with Iteration 6). That reduction was especially significant for neutrons, by $30 \%$. 


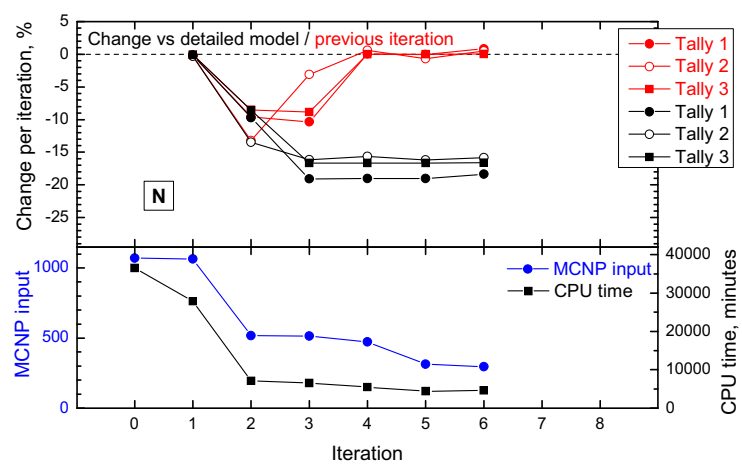

Fig. 13. The change in the neutron dose rates (upper plot) as well as the MCNP input file size and CPU time (lower plot) observed during Iteration $\# 6$.

The estimated photon and neutron effective doses and their relative change from both Iteration 0 and Iteration 6 are shown in Table 9. Removing the concrete floor produced an effect similar to the removal of the back, sides, and top of the glovebox and additional shielding in Iteration 2. The decrease in the dose rates was less than that observed in Iteration 2 because the distance between the tallies and the floor was greater than the distance between the tallies and the back, sides, and top of the glovebox and the additional shielding that was removed in Iteration 2. In addition, the magnitude of the decrease in the neutron dose rate was not as pronounced because concrete is not as effective moderator as PMMA. Fig. 15 presents the change in the neutron dose rates, the MCNP input file size, and CPU time observed during current iteration.

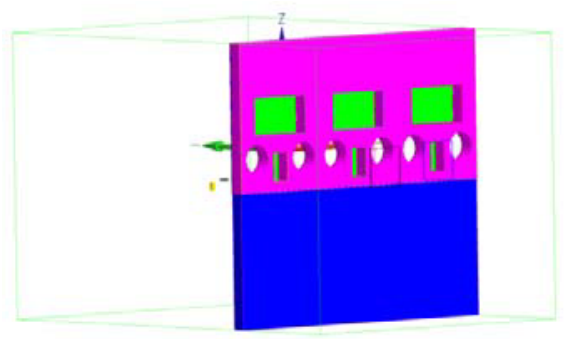

Fig. 14. MCNP glovebox model for Iteration 7: Removed Floor.

Table 9. Estimated Effective Dose Rates for Iteration 7: Removed Floor.

\begin{tabular}{|c|c|c|c|c|}
\hline \multirow{2}{*}{$\begin{array}{c}\text { Tally } \\
\#\end{array}$} & \multicolumn{2}{|c|}{$\begin{array}{c}\text { Estimated Dose } \\
\text { Rates, mrem/hr }\end{array}$} & \multicolumn{2}{c|}{$\begin{array}{c}\text { Percent Change vs } \\
\text { Iteration 0 / 6 }\end{array}$} \\
\cline { 2 - 5 } & Photon & Neutron & Photon & Neutron \\
\hline 1 & 0.491 & 3.75 & $63 /-0.7$ & $-21.3 /-3.6$ \\
\hline 2 & 0.923 & 2.23 & $309 /-0.3$ & $-19.0 /-3.8$ \\
\hline 3 & 0.756 & 8.20 & $31 /-0.4$ & $-17.7 /-1.3$ \\
\hline
\end{tabular}

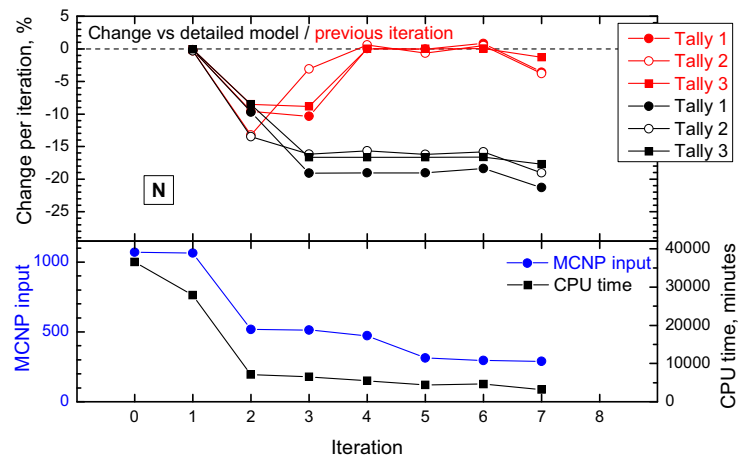

Fig. 15. The change in the neutron dose rates (upper plot) as well as the MCNP input file size and CPU time (lower plot) observed during Iteration \#7.

\subsection{Iteration 8: Removed Water Door}

The water door was removed in this iteration (see Fig. 16). This reduced the size of the input file to 278 lines. The CPU time for neutrons was increased by $10 \%$ (compare with Iteration 7).

The estimated photon and neutron effective doses and their relative change from both Iteration 0 and Iteration 7 are shown in Table 10. There was little change in the dose rates compared with the previous iteration, except the neutron dose rate was $12.5 \%$ less in Tally \#2. The decrease in the neutron dose rate in Tally \#2 upon the removal of the water door was an indicator that the geometry had been over-simplified. It should be noted that although the MCNP results for this iteration are correct, they are not realistic. Both the concrete floor and the water door scattered neutrons, allowing more neutrons to be sent in the direction of the tallies. Tallies $\# 1$ and 3 were too close to have additional neutrons scattered in their direction but Tally \#2 was sufficiently far enough from the glovebox to have additional neutrons scattered into it from both the concrete floor and the water door. Fig. 17 presents the change in the neutron dose rates, the MCNP input file size, and CPU time observed during current iteration.

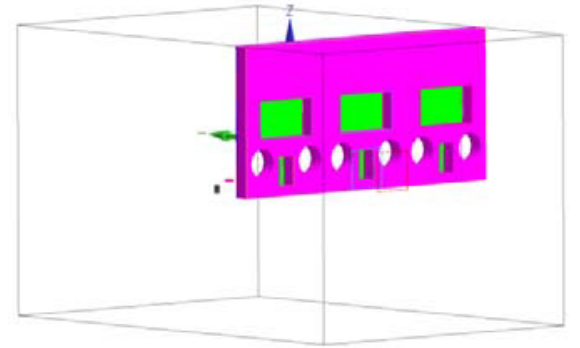

Fig. 16. MCNP glovebox model for Iteration 8: Removed Water Door.

\subsection{Additional Iteration: Removed Water Doors with Floor (Comparison with Iteration 6)}

In order to determine the level of influence the water door had on the estimated dose rates when there is radiation scattered on a concrete floor, the model from 
Iteration 6 was taken as a starting point and the water door was removed from it. The computational model for this additional iteration is presented in Fig. 18. The size of the input file was 283 lines. The CPU time for neutrons was decreased by $28 \%$ and for photons was increased by $5 \%$ (compare with Iteration 6 ).

Table 10. Estimated Effective Dose Rates for Iteration 8: Removed Water Door.

\begin{tabular}{|c|c|c|c|c|}
\hline \multirow{2}{*}{$\begin{array}{c}\text { Tally } \\
\#\end{array}$} & \multicolumn{2}{|c|}{$\begin{array}{c}\text { Estimated Dose } \\
\text { Rates, mrem/hr }\end{array}$} & \multicolumn{2}{c|}{$\begin{array}{c}\text { Percent Change vs } \\
\text { Iteration 0 7 }\end{array}$} \\
\cline { 2 - 5 } & Photon & Neutron & Photon & Neutron \\
\hline 1 & 0.493 & 3.69 & $63 / 0.5$ & $-22.4 /-1.5$ \\
\hline 2 & 0.931 & 1.95 & $312 / 0.8$ & $-29.0 /-12.5$ \\
\hline 3 & 0.741 & 8.05 & $29 /-2.0$ & $-19.1 /-1.8$ \\
\hline
\end{tabular}

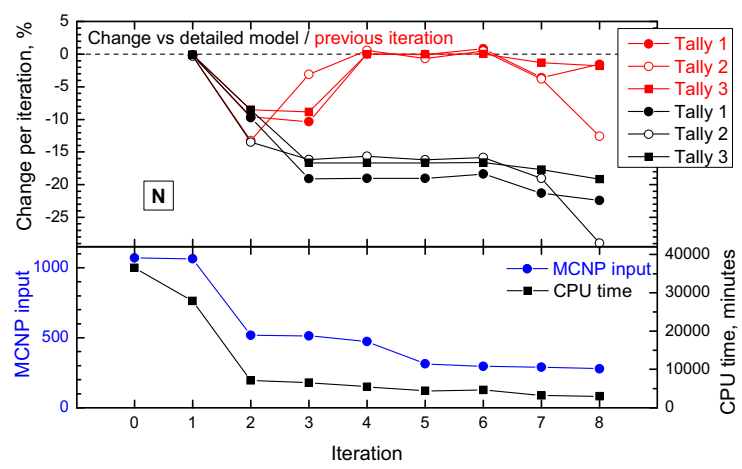

Fig. 17. The change in the neutron dose rates (upper plot) as well as the MCNP input file size and CPU time (lower plot) observed during Iteration \#8.

The estimated photon and neutron effective doses and their relative change from both Iteration 0 and Iteration 6 are shown in Table 11. As expected, both the photon and neutron dose rates increased when the water door was removed. This increase can be explained by an extra contribution of particles being scattered off the floor and being collected by the tallies. The most significant change was induced in Tally \#2. Which was the expected result considering that this Tally is more exposed to the radiation scattered off the floor than other tallies.

\section{Summary}

A summary of the effects on the dose rates from the various simplifications is presented in Fig. 19 for neutrons and Fig. 20 for photons. The summary of the MCNP input file size and the CPU time is shown in Table 1.

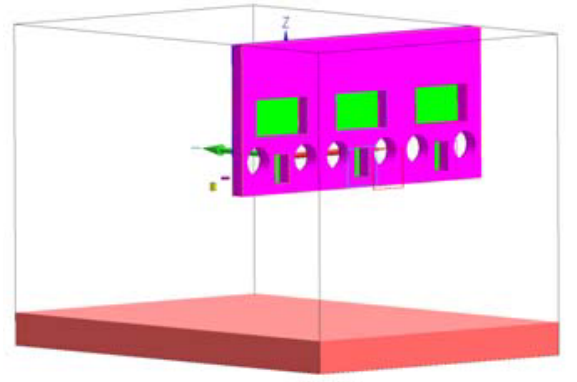

Fig. 18. MCNP glovebox model for the Additional Iteration: Removed Water Doors with Floor (Comparison with the Iteration 6).

Table 11. Estimated Effective Dose Rates for the Additional Iteration: Removed Water Doors with Floor (Comparison with the Iteration 6).

\begin{tabular}{|c|c|c|c|c|}
\hline \multirow{2}{*}{$\begin{array}{c}\text { Tally } \\
\#\end{array}$} & \multicolumn{2}{|c|}{$\begin{array}{c}\text { Estimated Dose } \\
\text { Rates, mrem/hr }\end{array}$} & \multicolumn{2}{c|}{$\begin{array}{c}\text { Percent Change vs } \\
\text { Iteration 0 / 6 }\end{array}$} \\
\cline { 2 - 5 } & Photon & Neutron & Photon & Neutron \\
\hline 1 & 0.529 & 4.22 & $75 / 6.9$ & $-11.3 / 8.7$ \\
\hline 2 & 0.990 & 2.78 & $338 / 6.9$ & $1.2 / 20.2$ \\
\hline 3 & 0.775 & 8.50 & $34 / 2.1$ & $-14.8 / 2.2$ \\
\hline
\end{tabular}

The analysis indicated that even the most simplified glovebox model doesn't result in a crucial deviation from the results obtained with a complex model. It was found that the iterations 2,3 , and the additional iteration from Section 3.9 produced the largest change in the estimated doses (excluding iteration 6 for photons when there was nothing between sources and tallies but atmospheric air). That change was about $10 \%$ per iteration for neutrons and up to $5 \%$ for photons.

The total change in neutron dose rates between the simple and complex model ranged from 20 to $30 \%$ and for photons was about 5\% (excluding 6 and subsequent iterations). Also the additional iteration (Section 3.9) demonstrated that some changes may compensate changes accumulated over other simplifying iterations. The main conclusion from the analysis is that it is possible to get a reasonable estimate of the anticipated dose rates using a simplified MCNP model. The level of the simplification can be selected based on the acceptable uncertainties in calculated dose rates.

The list below summarizes the findings of this exercise:

- A reduced outside world boundaries do not change the dose rates.

- Removing any additional bulky shielding placed on a glovebox or a structure element like a glovebox wall, which is close to a source, can result in underestimating the neutron dose rate by approximately $10 \%$ and the photon dose rate by approximately $5 \%$. 
- Adding complex geometry, such as curvatures, to windows, walls, etc. does not sufficiently influence either the photon or neutron dose rates.

- Adding structural details, which are sufficiently far from tally (like upper workstations in the model under consideration), does not influence either the photon or neutron dose rates.

- To avoid the significant contribution to the photon dose rate from low-energy photons, always place a material between the source and tally.

A good rule of thumb is start with the simplest approach. Complexity may be added to increase the accuracy of the model if the dose rates exceed or are close to the design limits.

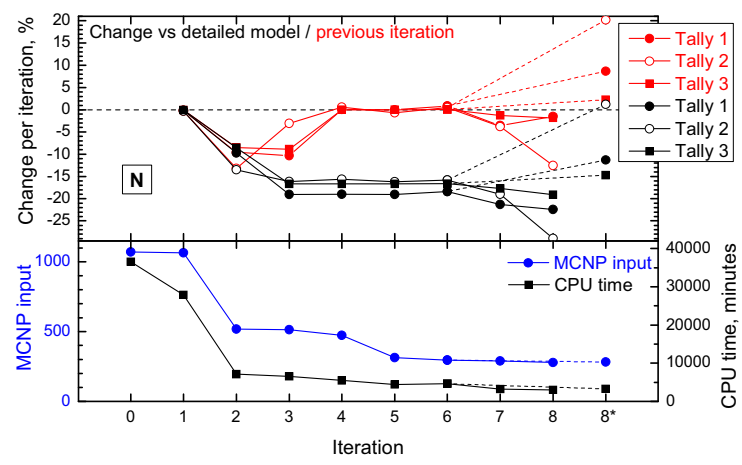

Fig. 19. Summary of the change in the neutron dose rates from the course of consequent iterations on the glovebox model simplification (upper plot) as well as a summary of the MCNP input file size and CPU time (lower plot). The additional iteration (Section 3.9) is marked as " $8 *$ ". Dashed lines represent a tendency of the change in the dose rates of this iteration after Iteration \#6.

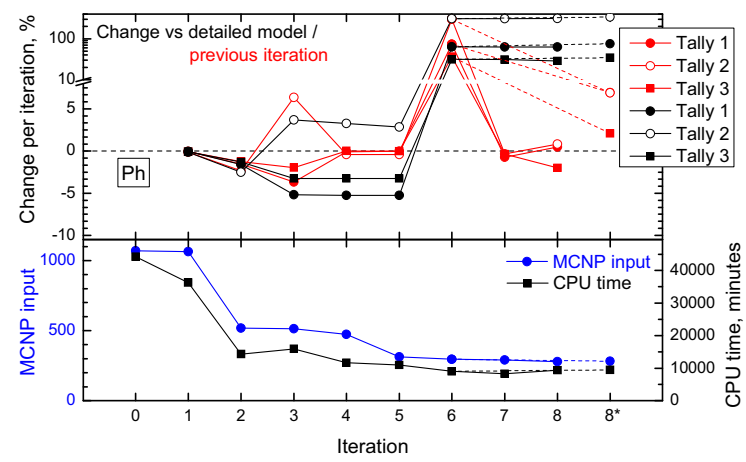

Fig. 20. Summary of the change in the photon dose rates from the course of consequent iterations on the glovebox model simplification (upper plot) as well as a summary of the MCNP input file size and CPU time (lower plot). The additional iteration (Section 3.9) is marked as " 8 *". Dashed lines represent a tendency of the change in the dose rates of this iteration after Iteration \#6.

\section{Conclusion}

The analysis indicated that most of the particle fluence across the tallies penetrated the front wall of the glovebox. Thus to obtain a fast and reasonable estimation of dose, the model should be realistic in details that are close to the tally. Other details may be omitted.

\section{Acknowledgment}

This work was conducted while in the LANL Group RPPROG. We wish to acknowledge the contributions made by the group members: J.M. Bean, C.J. Bianconi, M.A. Griffin, L.D. Hetrick, P.S. Hoover, B.T. Keller, G.R. Murrell, and R.C. Rangel.

\section{Reference}

1. X-5 Monte Carlo Team, MCNP - A General Monte Carlo N-Particle Transport Code, Version 5 (LAUR-03-1987, LANL, Los Alamos, 2003) 